\title{
FOCO NA INOVAÇÃO E COMPLEMENTARIDADE EM EQUIPES DE DIREÇÃO NO DESENVOLVIMENTO DE NOVAS EMPRESAS TECNOLÓGICAS
}

\author{
Focus on innovation and complementarity skills \\ in the manager team for the development of new \\ technology companies
}

Envio 09.11.09 / Aceite 07.12.09

\author{
Edmilson Lima ${ }^{2}$ \\ Vladas Urbanavicius Júnior ${ }^{3}$ \\ Emerson Antonio Maccari ${ }^{4}$ \\ Benny Kramer Costa ${ }^{5}$
}

\section{Resumo}

Muitas novas empresas de base tecnológicas são criadas devido às necessidades de produção e comercialização que se impõem aos aficionados em tecnologia que têm foco inicial apenas na inovação para a criação de produtos. Uma das conseqüências comuns deste foco exacerbado na inovação é a formação de equipes de direção, nas quais falta a complementaridade de alguém hábil como empreendedor e gestor de negócios. O objetivo deste trabalho é apresentar um estudo comparativo de casos de novas pequenas e médias empresas (PME) tecnológicas

\footnotetext{
${ }^{1}$ Este artigo se insere no fluxo de publicações iniciado a partir de Lima e Urbanavicius (2009), que fizeram uma versão preliminar do presente trabalho.

${ }^{2}$ Programa de Mestrado e Doutorado em Administração, Universidade Nove de Julho. E-mail: edmilsonolima@ gmail.com

${ }_{3}^{3}$ Programa de Mestrado e Doutorado em Administração, Universidade Nove de Julho. E-mail: vladasjunior@yahoo. com.br

${ }^{4}$ Programa de Mestrado e Doutorado em Administração, Universidade Nove de Julho. E-mail: emersonmaccari@ gmail.com

${ }^{5}$ Programa de Mestrado e Doutorado em Administração, Universidade Nove de Julho. E-mail: bennycosta@yahoo. com.br
} 
criadas por aficionados em tecnologia e da influência da complementaridade de habilidades entre os membros das equipes de direção sobre o desenvolvimento dessas empresas. O estudo identifica fatores viabilizadores e limitadores impostos pelo foco exacerbado na inovação. Ele também descreve algumas práticas úteis para se superar dificuldades provocadas pela falta de atenção inicial dos fundadores às competências empreendedoras e de gestão. A abordagem metodológica é descritiva e baseada em métodos qualitativos de pesquisa, integrando o estudo multi-caso (EISENHARDT, 1989). A coleta dos dados foi feita principalmente com entrevistas semiestruturadas em profundidade. A análise incluiu as etapas de análise intracaso e intercaso dos dados (MILES e HUBERMAN, 1994). Como resultado, verificou-se que a formação e o histórico das experiências dos diferentes fundadores se mostraram relevantes para explicar o tipo de foco dado à inovação tecnológica e às questões de negócio.

Palavras-chave: Inovação; Habilidades Complementares; Empresas de Base Tecnológica.

\begin{abstract}
new based technology companies are created to fulfill the needs of production and commercialization, but the entrepreneurs have only an initial focus on innovation to create products. The common consequence of this exaggerated focus on innovation is the formation of teams which lack some complementarity skills like entrepreneur and business manager. The objective of this work is to demonstrate a comparative case study of new small and medium based technology companies that were created by technology aficionados and the influence of complementarity skills between the team members on the direction for the development of these industries. The study identifies enablers and limiting factors due to exacerbated by the focus on innovation. It also describes some useful practices to overcome difficulties caused by the lack of initial attention of the founders in the entrepreneurial and management competence. The methodological approach is descriptive and based on qualitative research methods, integrating the study of multi (EISENHARD, 1989). Data collection was made with semi-structured interviews. The analysis of the gathered information adopted the steps of the intra and inter case recommended by (MILES and HUBERMAN, 1994). As a result, the formation and history of experiences of different founders showed to be relevant to explain the kind of focus given to technological innovation and business issues.
\end{abstract}

Keywords: Innovation; Complementarity Skills; Based Thecnology Companies.

\title{
1 Introdução
}

As pequenas e médias empresas (PME) tecnológicas normalmente apresentam um denominador comum: o interesse e o entusiasmo dos dirigentes fundadores pela tecnologia, base da criação dessas organizações. Mas isso não é suficiente para elas se desenvolvam adequadamente (BORGES, SIMARD e FILION, 2005; GARTNER, STARR e BHAT, 1999). Muitos recursos, tangíveis e intangíveis, devem ser utilizados para tanto. Contudo, estes recursos, incluindo conhecimentos e competências em tecnologia e em gestão, são muito escassos para as pequenas organizações, principalmente para aquelas que estão nascendo. É por isso que existem programas de incubação e de apoio para novas empresas tecnológicas, mantidos por órgãos governamentais e financeiros, por universidades e também pela iniciativa privada.

Considerando ou não a capacidade de atendimento limitada desses programas ou a possibilidade de procurar apoio de um deles, grande parte dos fundadores de empresas tecnológicas busca suas formas de superar as severas restrições de recursos típicas em sua realidade. Uma das mais comuns é a formação de equipes de direção, composta por sócios-

Rev. Adm. UFSM, Santa Maria, v. 2, n. 2, p. 343-357, maio/ago. 2009 
dirigentes que possam oferecer à nova empresa recursos complementares (KAMM et al., 1990; UCBASARAN et al., 2001; UCBASARAN et al., 2003), principalmente recursos financeiros e competências tecnológicas. Isso contribui para a predominância das equipes de direção nos processos de criação de empresas tecnológicas, predominância já destacada por diferentes autores, como, por exemplo, Christensen, Ulhoi e Neergaard (2001) e Stockley e Birley (2000).

Com seu entusiasmo por produtos tecnológicos, os fundadores encontram a energia e a criatividade para empreender e criar novas empresas, gerando benefícios para si mesmos e para a sociedade. O foco na inovação tecnológica é, portanto, um importante viabilizador de novas empresas tecnológicas, mas, ao mesmo tempo, pode ser um limitador. Ele pode desviar a atenção dos empreendedores de questões essenciais para o desenvolvimento dessas empresas, como a gestão. Não por acaso um erro comum na formação das equipes de direção de novas empresas tecnológicas é a falta de um membro que complemente a capacidade de ação dessas equipes com competências na área de administração. Muitos estudos mostram que as PME fundadas e administradas por uma equipe de direção têm, em média, mais sucesso do que as outras (LECHLER, 2001), mas a complementaridade e a diversidade adequadas dos membros dessas equipes são fundamentais (UCBASARAN et al., 2001).

O objetivo deste trabalho é o de apresentar um estudo comparativo de alguns casos de novas PME tecnológicas criadas por aficionados em tecnologia, dando especial atenção àqueles casos cujo foco das atividades se limitava, essencialmente, à geração de inovações tecnológicas. O estudo teve por finalidade identificar, nas PME, fatores viabilizadores e limitadores gerados pelo foco exacerbado na inovação tecnológica para a criação e o desenvolvimento das empresas. Outro interesse foi descrever práticas úteis para se superar dificuldades provocadas pela falta de atenção inicial dos fundadores às competências empreendedoras e de gestão.

Este artigo tem a seguinte estrutura: na seção 2, a seguir, ele apresenta uma breve revisão de literatura e, em seguida, na seção 3, explicita os métodos de pesquisa deste estudo empírico, cujos resultados são expostos na seção 4; a seção 5 finaliza o trabalho com as conclusões.

\section{Equipes de direção e novas PME tecnológicas}

Dada a predominância das equipes de direção à frente das novas PME tecnológicas, o conhecimento dos diferentes aspectos relacionados a tais equipes são relevantes para se entender o desenvolvimento dessas empresas. Um deles refere-se à complementaridade de competências e atividades entre os membros dessas equipes. A partir da revisão de diferentes estudos sobre a criação de empresas tecnológicas, Borges, Simard e Filion (2005) sustentam que as equipes de direção estão, na maior parte dos casos, preparadas para as funções técnicas, como as de pesquisa e desenvolvimento (PeD) e de produção, dadas as suas competências e experiências, geralmente, obtidas na área tecnológica. Contudo, os mesmos autores informam que a literatura (ALBERT, 2000; GARTNER, STARR e BHAT, 1999; JONES-EVANS, 1997) destaca que, geralmente, faltam a essas equipes competências muito importantes para assegurar bons resultados para as novas empresas: em marketing e vendas, em gestão e em finanças e contabilidade.

Clarysse e Moray (2004) relatam o paradoxo que os membros dessas equipes enfrentam, figurando como heróis da criação tecnológica e como anti-heróis na gestão dos novos negócios. Nessa realidade, eles se deparam com a necessidade de reforçar sua complementaridade, como condição para atender às necessidades de desenvolvimento desses negócios e lidar com a complexidade organizacional. Uma possibilidade seria a contratação de um gerente 
executivo. Mas há barreiras para se contratar um gestor no início do empreendimento. Além da forte restrição de recursos, é raro que os inventores da nova tecnologia não queiram, eles mesmos, dirigir os negócios criados para comercializá-la e se manter como os únicos sócios neles (CLARYSSE e MORAY, 2004) ${ }^{6}$.

Reconhecendo as limitações de competência em gestão comuns nas novas PME tecnológicas, variados programas de incubação, de apoio dos órgãos de fomento, de oferta de capital de risco e de capacitação (como aqueles do SEBRAE, no Brasil) incluem reforço dirigido às atividades de administração dessas empresas. Por exemplo, as empresas de capital de risco, com frequência indicam um administrador para complementar o trabalho dos dirigentes da PME tecnológica nos aspectos de gestão, com isto, elas aumentam a possibilidade de retorno de seu investimento.

\subsection{Complementaridade na equipe de direção das PME}

A interação e a complementaridade dos dirigentes no seio da equipe de direção é determinante para as PME, como indicam os estudos empíricos e de revisão de literatura feitos por Lima (2004, 2007a,b, 2009). Os resultados das pesquisas deste autor mostram que, além de se somar ou combinar para cobrir o espectro de necessidades das PME, as atividades e competências dos membros das equipes de direção de PME tecnológicas e não tecnológicas atingem certo nível de complementaridade por intermédio da comunicação e, principalmente, por meio do processo identificado como conversa estratégica. Esse processo pode ser definido como uma manifestação das relações entre duas ou mais pessoas, pela qual uma pode comunicar a outra suas ideias, opiniões, visão e imagens no que diz respeito a questões estratégicas de uma dada organização (LIMA, 2004, 2007a,b).

Por tornar possível a transmissão, entre diferentes atores, de elementos da subjetividade relativos a questões estratégicas, a conversa estratégica constitui um dos principais processos que levam ao estabelecimento dos itens de orientação estratégica (missão, visão e objetivos) que se tornam compartilhados entre os dirigentes e que eles buscam compartilhar com os demais membros de sua PME. A visão (imagem mental de um futuro desejado a realizar) que motiva e norteia o desenvolvimento de inovações e a criação de uma PME tecnológica é, comumente, o fruto deste processo (LIMA, 2009).

$\mathrm{Na}$ conversa estratégica, a participação de cada dirigente é moldada por seu campo de atividades e por seu campo de competências. O campo de atividades de um membro em uma organização é o campo de trabalho que lhe foi atribuído pela diretoria. Essa atribuição gera expectativas quanto ao papel desse ator. Assim, espera-se que um diretor incumbido da administração financeira realize, por exemplo, a coordenação das atividades de previsão orçamentária da organização. Por outro lado, não se espera que essa pessoa conduza a realização de pesquisas de mercado em marketing.

O campo de competências de um membro agrega os elementos que lhe dão o poder de mudança de sua realidade, segundo sua vontade e/ou seus projetos, como capacidades, habilidades e conhecimentos. Tais elementos são influenciados, entre outras coisas, pela vivência desse indivíduo, sua formação, sua história familiar e sua capacidade de aprendizagem. Os indivíduos desenvolvem seu campo de competências aprendendo ao longo da vida.

\footnotetext{
${ }^{6} \mathrm{~A}$ partir daí, os autores sugerem que a complementaridade adequada pode ser atingida não pela contratação de um gestor, mas de um tutor (coach), o que permitiria que a equipe desenvolvesse gradualmente nela mesma as novas competências necessárias.
} 
A complementaridade dos dirigentes quanto a seu campo de atividades e a seu campo de competências é fundamental para a qualidade das decisões que eles tomam coletivamente. Ela é especialmente importante para assegurar a coerência dessas decisões com a realidade das PME estudadas. Por exemplo, se a equipe de direção não tem um dirigente com competências suficientes para Ihe auxiliar a cobrir as necessidades das atividades de marketing da empresa, os aspectos da visão compartilhada relativos ao dimensionamento e à caracterização da clientelaalvo, entre outras coisas, podem ser pouco realistas. Esse tipo de limitação pode gerar grandes prejuízos a uma PME.

No caso da empresa canadense do ramo de moda Poitra Design, uma das PME estudadas por Lima $(2004,2007 a$, b), vê-se que a complementaridade na equipe de direção foi falha quanto à administração interna (de pessoal e de produção, por exemplo), enquanto os dois dirigentes cobriam adequadamente as necessidades ligadas às atividades de criação de novos produtos em moda, de marketing e de vendas. Ao longo dos anos, o foco excessivo no desenvolvimento dos produtos e em suas vendas, sem os devidos cuidados com a administração interna, levou a PME a enfrentar grandes problemas, como custos crescentes, descompassos do processo produtivo e falhas de qualidade. Além disso, os elementos de orientação estratégica eram continuamente estabelecidos com limitações relativas à administração interna. À medida que eles eram realizados, como ocorria com a visão compartilhada deficiente da equipe de direção, os problemas tendiam a se agravar. Essas dificuldades contribuíram para o posterior encerramento das atividades da Poitras Design.

Exemplo diferente vem da PME tecnológica Benner, sediada na cidade de Blumenau, Brasil (LIMA, 2006; ZOSCHKE, 2006). Essa empresa foi criada por uma equipe de direção de três dirigentes, com competências concentradas majoritariamente em tecnologia, mas um deles apresentando perfil empreendedor e habilidades em gestão empresarial voltados para empresas produtoras de software. Com erros (como a dependência durante um período de um só grande cliente que apresentou dificuldades para realizar seus pagamentos) e acertos (por exemplo, a empresa foi fundada segundo as orientações traçadas em um plano de negócios que gerou muitos acertos) nos primeiros anos da Benner, a equipe teve a possibilidade de aperfeiçoar suas competências em gestão e assegurou um desenvolvimento sólido para a empresa.

\section{Métodos de pesquisa}

O estudo multi-caso qualitativo, inspirado principalmente nas propostas de Eisenhardt (1989), foi escolhido como modelo básico para a pesquisa. Segundo Yin (2001), essa modalidade de estudo assegura a profundidade e a contextualização no estudo do fenômeno enfocado ao mesmo tempo em que diminui a dificuldade de generalização característica dos estudos de um só caso. Yin (2001) acrescenta que os estudos de caso são especialmente apropriados para se responder perguntas de pesquisa como a do estudo realizado, que começam com "como" e "por que". Tais perguntas pedem uma perspectiva metodológica descritiva.

Uma exceção no emprego que fizemos da proposta indutivista de Eisenhardt (1989) refere-se à recomendação feita por essa autora para que se evite o uso de teorias no início da pesquisa. Fizemos uma revisão de literatura e uma fundamentação teórica. Isso nos pareceu necessário para identificarmos uma necessidade de pesquisa que justificasse nosso estudo a explorar e para formarmos as bases da perspectiva teórico-conceitual a aplicar no esforço de pesquisa. Fizemos também a preparação prévia de parte considerável dos procedimentos de coleta e de análise de dados antes da pesquisa de campo. Quando dessa preparação, consideramos nossos conhecimentos prévios e contribuições de outros autores para desenvolver 
preliminarmente itens como o roteiro de entrevista e para identificar alguns conceitos relevantes para a análise dos dados. De toda forma, não perdemos de vista o caráter cíclico da pesquisa qualitativa.

Essas exceções ao uso das propostas de Eisenhardt (1989) aproximam ligeiramente as opções metodológicas do estudo das propostas de Yin (2001), autor que defende o desenvolvimento detalhado a priori de muitos aspectos do estudo de caso. Assim, a abordagem utilizada foi, predominantemente, indutiva, mas com traços dedutivos, principalmente nas exceções apontadas.

A amostra de PME tecnológicas que foi estudada é apresentada no Quadro 1.

\begin{tabular}{|c|c|c|}
\hline $\begin{array}{l}\text { PME tecnológica } \\
\text { (condição no ciclo de vida) } \\
\text { Fundação - Localização }\end{array}$ & $\begin{array}{c}\text { Direção } \\
\text { № de } \\
\text { membros/tipo }\end{array}$ & Atividade/Produtos \\
\hline $\begin{array}{l}\text { Hábeis Soluções } \\
\text { (crescimento) } \\
\text { 2001/Santa Rita do Sapucaí, MG. } \\
\text { Empresa graduada na incubadora } \\
\text { de empresas do INATEL. }\end{array}$ & 2 (familiar) & $\begin{array}{l}\text { Setor: informática/6 empregados } \\
\text { PME especializada no desenvolvimento de soluções } \\
\text { integradas de hardware e software para produtos } \\
\text { eletroeletrônicos em geral, utilizando microcontroladores e } \\
\text { tecnologia DSP. Ver: http://www.habeis.com.br }\end{array}$ \\
\hline $\begin{array}{l}\text { Exsto Tecnologia } \\
\text { (crescimento) } \\
\text { 2001/Santa Rita do Sapucaí, MG. } \\
\text { Empresa graduada no Programa } \\
\text { Municipal de Incubação de } \\
\text { Empresas (PROINTEC). }\end{array}$ & $\begin{array}{l}2 \\
\text { (não-familiar) }\end{array}$ & $\begin{array}{l}\text { Setor: eletrônica, mecatrônica, automação /30 } \\
\text { empregados } \\
\text { - Educação: produtos voltados para escolas e professores nas } \\
\text { áreas de eletrônica, mecatrônica e automação industrial para } \\
\text { equipar os laboratórios de cursos técnicos e superiores; } \\
\text { - Desenvolvimento: produtos para qualificar e dar o suporte } \\
\text { para que desenvolvedores de software sejam mais eficientes. } \\
\text { Ver: http://www.exsto.com.br }\end{array}$ \\
\hline
\end{tabular}

Fonte: Os autores.

Quadro 1 - Composição da amostra de PME estudadas.

Os critérios de seleção da amostra de casos e dos informantes privilegiaram a escolha de empresas de menos de 250 empregados - possibilitando a inclusão também de microempresas na amostra. Com isso, buscamos assegurar a pertinência e a relevância das informações derivadas da coleta de dados em relação ao tema central do estudo. Em maior detalhe, as empresas estudadas foram escolhidas de forma intencional, não-probabilística, com alta correspondência com os seguintes critérios de seleção: 1) ter as características qualitativas de uma PME, apresentando propriedade e administração independentes de qualquer outra empresa, administração personalizada (refletindo a figura de seus proprietários) e uma pequena fatia de mercado; 2) respeitar o critério quantitativo de menos 250 empregados; 3) ter uma equipe de direção configurada na composição societária (formal ou informalmente) e possibilitar entrevistas com, no mínimo, dois dirigentes que forneçam detalhes ocorridos desde a fundação; 4) ter ao menos um ano de existência. Definimos aqui a equipe de direção como sendo uma equipe composta de proprietários-dirigentes de uma empresa, que sejam encarregados da gestão estratégica, e do presidente do conselho de administração (CA), se houver um CA na empresa.

Os procedimentos de coleta dos dados da pesquisa basearam-se principalmente em entrevistas semiestruturadas em profundidade com duração média de duas horas e meia e utilização de um roteiro semiestruturado de entrevista. Os dados foram obtidos principalmente por meio de fontes primárias de informação, ou seja, por entrevistas gravadas com dirigentes das PME da amostra. Fotos, artigos de jornais e informativos impressos das empresas estudadas foram fontes de informação secundária, utilizadas para realizar a triangulação e a consequente validação dos dados. De acordo Flick (2004), a triangulação consiste na utilização de diferentes 
fontes de dados e de variados métodos para sua coleta, com o objetivo de checar sua validade por meio de comparações.

Ao realizar a análise dos dados, os pesquisadores se concentraram na análise em profundidade dos dados relativos a cada PME (análise intracaso dos dados) e na análise comparativa dos casos (análise intercaso dos dados) das constatações emergentes dos diferentes casos, segundo as recomendações de Miles e Huberman (1994).

\section{Dados e resultados da pesquisa}

A análise dos dados nas duas PME estudadas foi realizada de forma separada e, depois, em conjunto, pela comparação dos dois casos de empresa, o que permitiu que fossem formuladas várias contribuições para descrever as influências do foco na geração de inovações tecnológicas e da complementaridade dos membros das equipes de direção sobre o desenvolvimento das PME tecnológicas. Primeiramente, foi possível identificar alguns fatores geradores de novas empresas (FGNE) tecnológicas. Em um segundo momento, a análise permitiu verificar vários fatores que levam à formação das equipes de direção das PME tecnológicas. Em seguida, foi possível identificar algumas das dificuldades geradas pelo foco em inovação tecnológica dos dirigentes acompanhado da competência restrita em gestão. Em uma quarta etapa, foram verificados os benefícios gerados pelo foco em inovação tecnológica, apesar de sua limitação quanto à gestão. Na última análise, identificamos algumas das práticas úteis utilizadas pelos dirigentes para superar as deficiências geradas por seu foco acentuado na inovação.

\subsection{Fatores geradores de novas empresas (FGNE) tecnológicas}

A análise do que leva à criação de uma PME tecnológica mostra que alguns fatores, isolados ou conjugados, favorecem o surgimento da nova empresa. Os FGNE em questão são aqueles que interferiram na criação das empresas que compõem a amostra da pesquisa. Eles são: base prática, base teórica, base estrutural, base de acesso, base intuitiva e base de interesse.

A base prática pode ser entendida como as experiências em outros negócios, similares ou não aos da nova empresa, formais ou não, que os dirigentes acumularam. Essas experiências favorecem o entendimento do funcionamento de uma empresa tecnológica, de suas possibilidades e dificuldades, dando segurança e certo nível de competência de trabalho aos dirigentes. O trecho de entrevista a seguir traz um exemplo:

Eu comecei prestando serviços de modo informal para diversas empresas de Santa Rita do Sapucaí. Eu tinha acesso aos produtos dos clientes, fui identificando diversas falhas no projeto deles. Quando os clientes iam fazer o primeiro protótipo, eu encontrava muita deficiência nos circuitos eletrônicos... Dessa forma, fui aprendendo o que os empresários faziam de bom e também de ruim; fui aprendendo a projetar, utilizando toda a estrutura que o Instituto Nacional de Telecomunicações (Inatel) disponibilizava para pesquisa. Pude conviver no ambiente de muitas empresas e de setores variados ligados a eletrônica, o que me deu base para abrir a minha empresa. Além disto, a proximidade com as empresas clientes possibilitou uma ampla rede de contatos favoráveis ao sucesso dos meus negócios. (José Dardier, sóciodirigente na Hábeis Soluções).

A fonte da base teórica está relacionada, normalmente, a algum centro de pesquisa ou instituição de ensino. No caso das empresas pesquisadas, em ambas, os dirigentes possuíam 
algum vínculo ou com o Inatel ou com a Faculdade de Administração e Informática (FAl), o que teve influência importante no processo de criação das PME.

A base estrutural também foi identificada como importante para o processo gerador da nova empresa tecnológica e, nos casos em estudo, este apoio estava relacionado, principalmente, com vantagens oferecidas por órgãos de apoio (incubadoras, por exemplo) e pelo próprio município de Santa Rita do Sapucaí.

A base de acesso se constitui na rede de relação dos dirigentes e se mostrou fundamental para a busca de novos sócios-dirigentes e para a formação das equipes de direção, assim como na obtenção de acesso a informações relevantes e aos clientes.

A base intuitiva está relacionada a outros fatores geradores da nova empresa, constituindo-se como um resultado geral de várias conexões de conhecimento, experiência e relacionamento que os sócios obtiveram.

A base de interesse está ligada ao fator motor, à motivação ou estímulo interior dos sócios-dirigentes na geração da nova empresa.

Os FGNE podem ser visualizados na Figura 1.

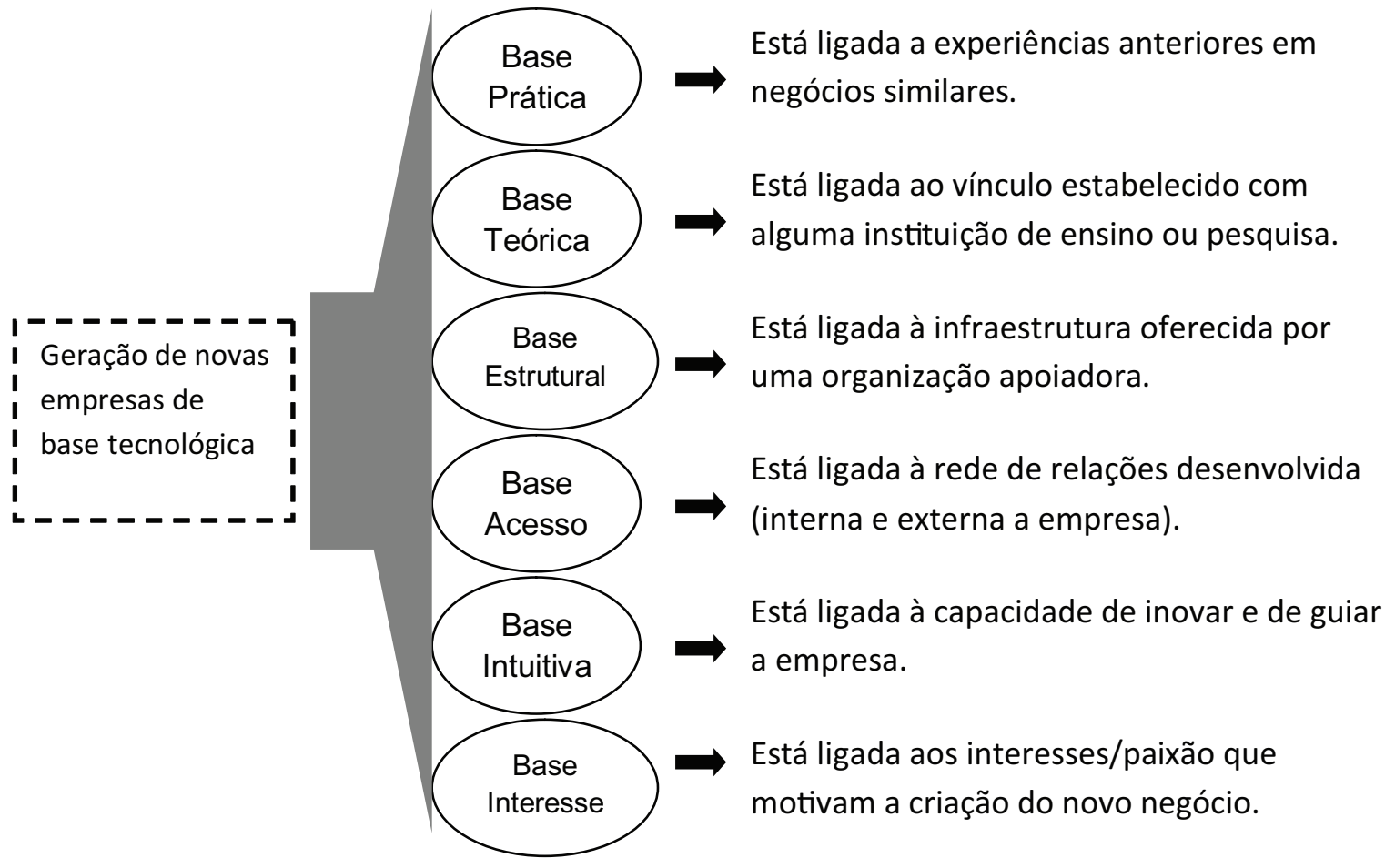

Fonte: os autores.

Figura 1 - Fatores geradores de novas empresas (FGNE).

\subsection{Fatores que levam à formação de equipes de direção nas PME tecnológicas}

Entre os fatores associados à busca de sócio-dirigente, que gera uma equipe de direção, estão: insegurança, vínculo pessoal, agregar conhecimento para desenvolver o produto, falta de tempo, agregar conhecimento de gestão e obtenção de recursos financeiros (ver Figura 2).

A inexperiência como empresário pode levar a um sentimento de insegurança com relação à nova empresa. A presença de um sócio foi relatada como um fator de apoio, pelo menos no início do empreendimento. Os vínculos de amizade e familiar também foram indicados 
como importantes no surgimento da sociedade. O desenvolvimento do conhecimento técnico não é simples, e a complementaridade tecnológica também se mostrou importante na busca do novo sócio-dirigente.

Adicionalmente, a falta de tempo foi indicada como um fator que leva à busca de um sócio, principalmente pelo fato de que, muitas vezes, os sócios de empresas tecnológicas se encontrarem na condição de estudantes, sem tempo para dedicar integralmente ao novo empreendimento.

A complementaridade de um sócio visando a cobrir as necessidades de gestão da empresa foi indicada como importante pelos entrevistados. Um outro dado relevante que as amostras da pesquisa possibilitaram apurar é que, em ambas as PME estudadas, os sócios responsáveis pela gestão não apresentavam formação em Administração, mas sim certa habilidade despertada por suas experiências e aprimorada com treinamentos e trocas de experiência.

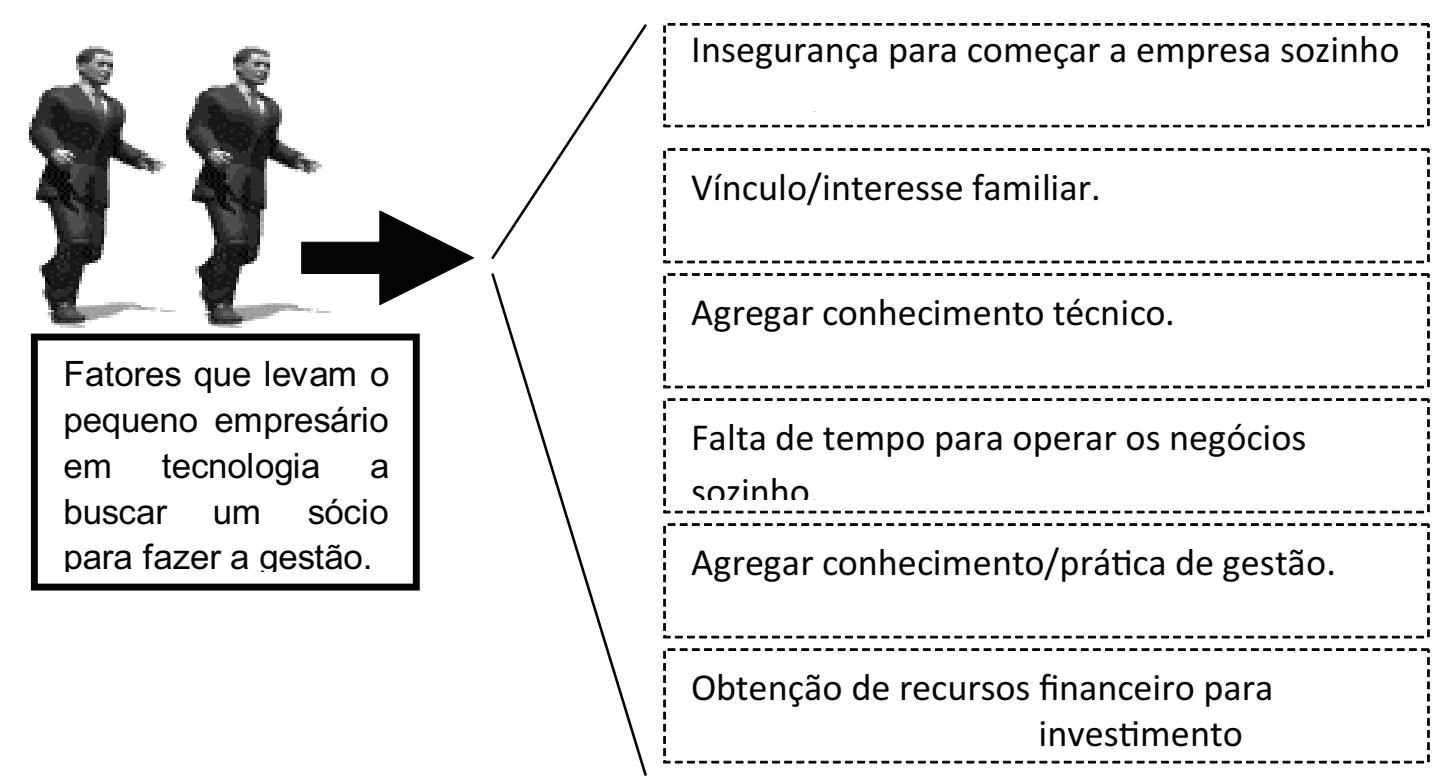

Fonte: os autores.

Figura 2 - Fatores que levam o empresário em tecnologia a buscar sociedade/parceria de gestão.

Como também indicaram as entrevistas, um sócio-dirigente apresenta um adicional de recursos financeiros, o que se torna importante para a nova empresa, seja no investimento inicial, seja na divisão dos custos fixos no período em que a empresa normalmente não apresenta lucro.

\subsection{Dificuldades advindas do foco na inovação acompanhado de competências restritas em gestão}

Segundo os relatos obtidos, ao mesmo tempo que gera benefícios, o foco exacerbado na inovação tecnológica e nos produtos limita os dirigentes, podendo levá-los à falta de entendimento do mercado. A empolgação com a inovação tecnológica gera efeitos indesejados, principalmente quando não está amparada no estudo do mercado para se identificar as reais 
necessidades dos clientes visados e inferir sobre as potencialidades das inovações geradas sob forma de bens ou serviços a comercializar.

Outro fator prejudicial do preparo dos dirigentes exclusivamente na área tecnológica é que eles tendem a se comportar simplesmente como criadores de inovações tecnológicas, e não como empresários, de modo mais amplo, empregando as atividades e cuidados necessários ao desenvolvimento da PME.

Isto é ilustrado pelo relato a seguir de um dos dirigentes entrevistados:

\begin{abstract}
A empresa tinha muitos custos de retrabalho. Começamos a culpar um ao outro ao invés de pararmos para conversar e discutir possíveis soluções. Meu sócio, então, resolveu que tinha que assumir a parte de gestão e eu a parte de desenvolvimento de produtos. Mas as coisas já não estavam boas nesta época e tudo se complicou mais. Ele ainda precisava aprender muita coisa de gestão de empresa justamente em um momento em que não se podia errar. Foram dados muitos passos errados. Começou, então, a dissolução da empresa, com muitos conflitos [...] cada um afirmando que estava certo com relação às suas ideias para os negócios. O passo final para o fechamento da empresa se deu em uma feira em que participamos em São Paulo. Nós dois, na mesa de negociação com um cliente, fomos abertamente contrários um ao outro sobre a possibilidade de entrega de produtos em uma certa data. Ao invés de fazermos uma reunião em particular, a discussão ocorreu na frente do cliente. Nós viemos de São Paulo para Santa Rita do Sapucaí discutindo o problema. Passado um mês do ocorrido, chegamos à conclusão de que o melhor seria dividir a sociedade. Tínhamos que nos acertar trabalhando juntos ou separados (José Dardier, sócio-dirigente na Hábeis Soluções).
\end{abstract}

Foi também relatada pelos entrevistados a necessidade de se delegar, uma vez que há acúmulo de tarefas em decorrência do forte vínculo com atividades operacionais ligadas ao desenvolvimento dos produtos.

A Figura 3 sintetiza as dificuldades elencadas nesta seção do texto.

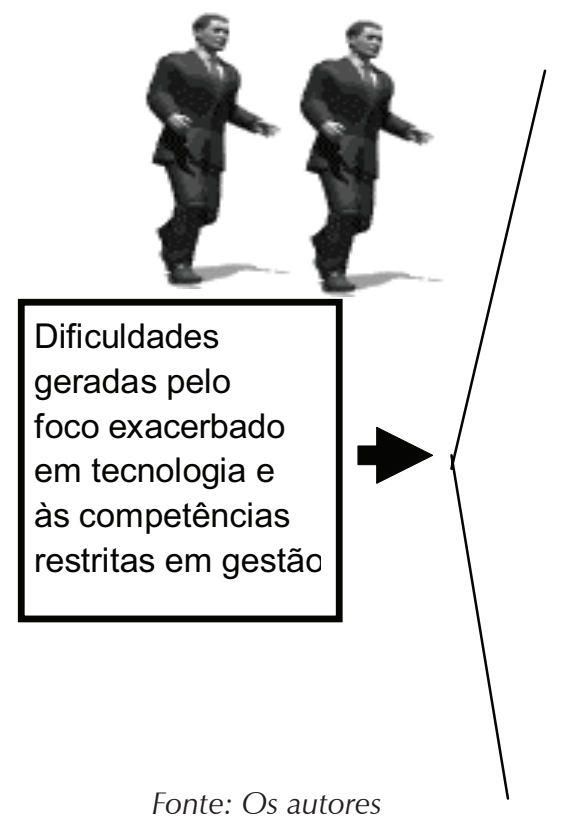

Empolgação demasiada com a componente tecnológica da idéia de negócios.

Falta de análise de mercado e fraco conhecimento. dele

Graves erros na condução dos negócios.

Falta de distinção dos papéis de projetista tecnológico e de empresário.

Tendência a conflitos e dificuldade em resolvê-los.

Dificuldade em delegar atividades a terceiros.

Figura 3 - Dificuldades geradas pela vocação tecnológica aliada à falta de conhecimento em gestão.

Rev. Adm. UFSM, Santa Maria, v. 2, n. 2, p. 343-357, maio/ago. 2009 


\subsection{Benefícios gerados pelo foco em inovação tecnológica}

O domínio sobre diversos aspectos do desenvolvimento de produtos foi apontado como um importante benefício gerado pela vocação tecnológica dos dirigentes. O domínio da tecnologia dá flexibilidade e independência para a empresa. Tal domínio mantém baixo o custo de desenvolvimento dos produtos, tornando a criação de uma empresa tecnológica acessível aos aspirantes a empresário que possuem pouco capital para investir.

Ao buscar competências tecnológicas, participando de cursos em universidades e outros ambientes de aprendizagem, os dirigentes desenvolvem também uma rede de relação que se torna muito útil para sua empresa. Ao enfrentar dificuldades no desenvolvimento dos produtos, ou mesmo em outras questões, com frequência, eles recorrem a esta rede de relações para obterem apoio.

O domínio da tecnologia também favorece a compra de matéria-prima, uma vez que os dirigentes podem analisar com acuidade qual o tipo de fornecedor e qual o componente mais adequado para desenvolver os produtos. Por dominarem a tecnologia que exploram, facilitam-se as melhorias de produto a baixo custo, assim como seu aperfeiçoamento contínuo.

O domínio da tecnologia viabiliza a criação de produtos nos moldes solicitados pelo comprador e sua adaptação às novas exigências do mercado. Este domínio também facilita a comunicação técnica com o cliente, inspirando confiabilidade nas relações de negócios.

A realização pessoal também é um fator favorável, uma vez que os dirigentes normalmente escolhem trabalhar em uma área que lhe agrada.

Os benefícios citados nesta seção estão resumidos na Figura 4.

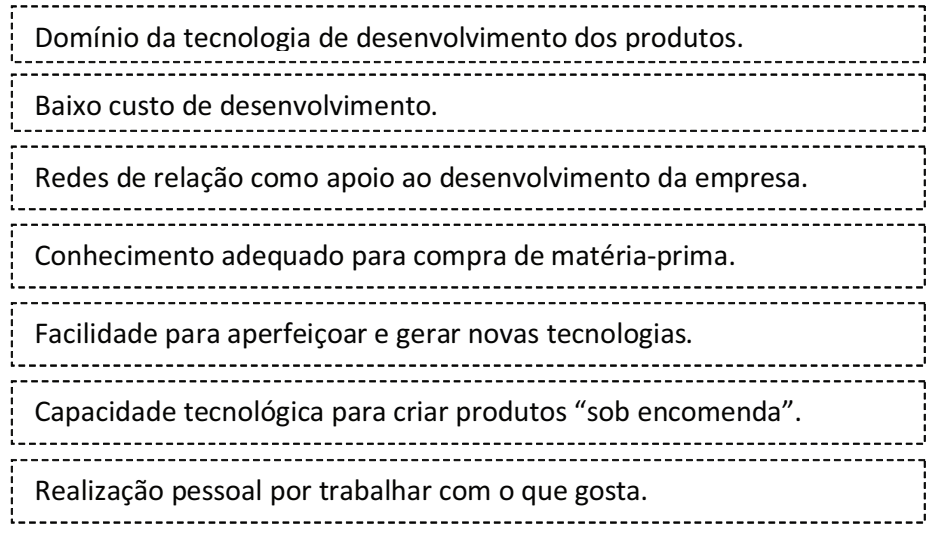

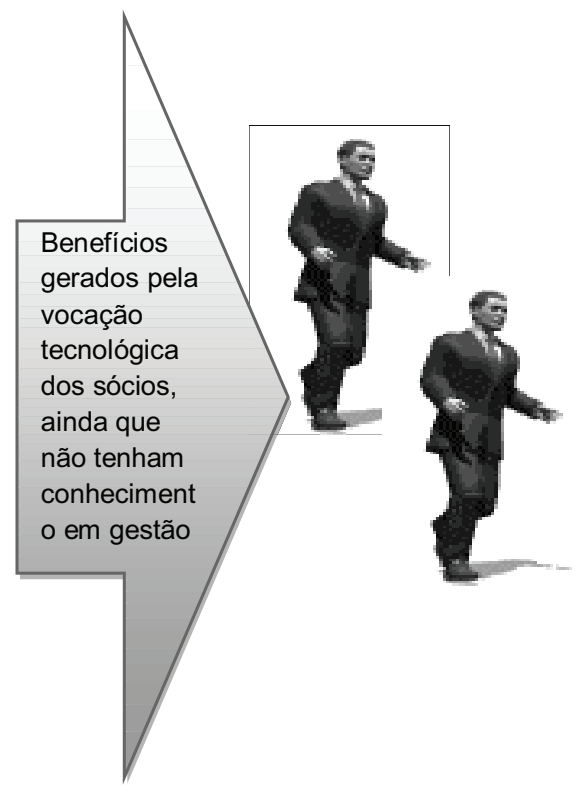

Fonte: os autores.

Figura 4 - Benefícios do foco em inovação. 


\subsection{Práticas para superar as limitações impostas pelo foco em inovação e pela competência restrita em gestão}

Uma das práticas utilizadas pelos dirigentes para se superar as limitações decorrentes do foco em inovação e da competência restrita em gestão é a troca de experiência com dirigentes de outras empresas tecnológicas. Como as empresas em estudo estão localizadas em Santa Rita do Sapucaí, estado de Minas Gerais (Brasil), uma pequena cidade que sedia em torno de 120 empresas tecnológicas, existe uma elevada proximidade entre os empresários, o que favorece o estabelecimento de redes de relação propícias ao desenvolvimento de cada uma das empresas. Essas constatações convergem com os resultados de pesquisa de Lima (2005). A compensação das limitações de habilidades de gestão ao longo dos primeiros anos de criação das PME está sob forte influência da rede de relação dos fundadores, da capacidade de auxílio desta rede e da capacidade dos fundadores para buscar tal auxílio. Destaca-se que a certificação com normas de qualidade mostrou-se uma prática de gestão que gera resultados positivos.

A pesquisa mostrou que a facilidade de acesso à consultoria especializada também contribui para gestão das empresas. Aliado à consultoria, houve ênfase para a utilização de softwares de gestão, favorecendo o controle e levando os empresários a certa disciplina administrativa, uma vez que é preciso alimentar os dados.

A participação em cursos rápidos de gestão, envolvendo as diversas áreas da administração, mostrou-se uma ajuda importante para melhorar as habilidades de administração dos dirigentes na criação das empresas e na implantação de novos instrumentos de gestão. Assim, a pró-atividade na montagem da equipe de direção e na preparação de seus membros é importante para diminuir as dificuldades das PME tecnológicas em sua fase de criação (Figura $5)$.

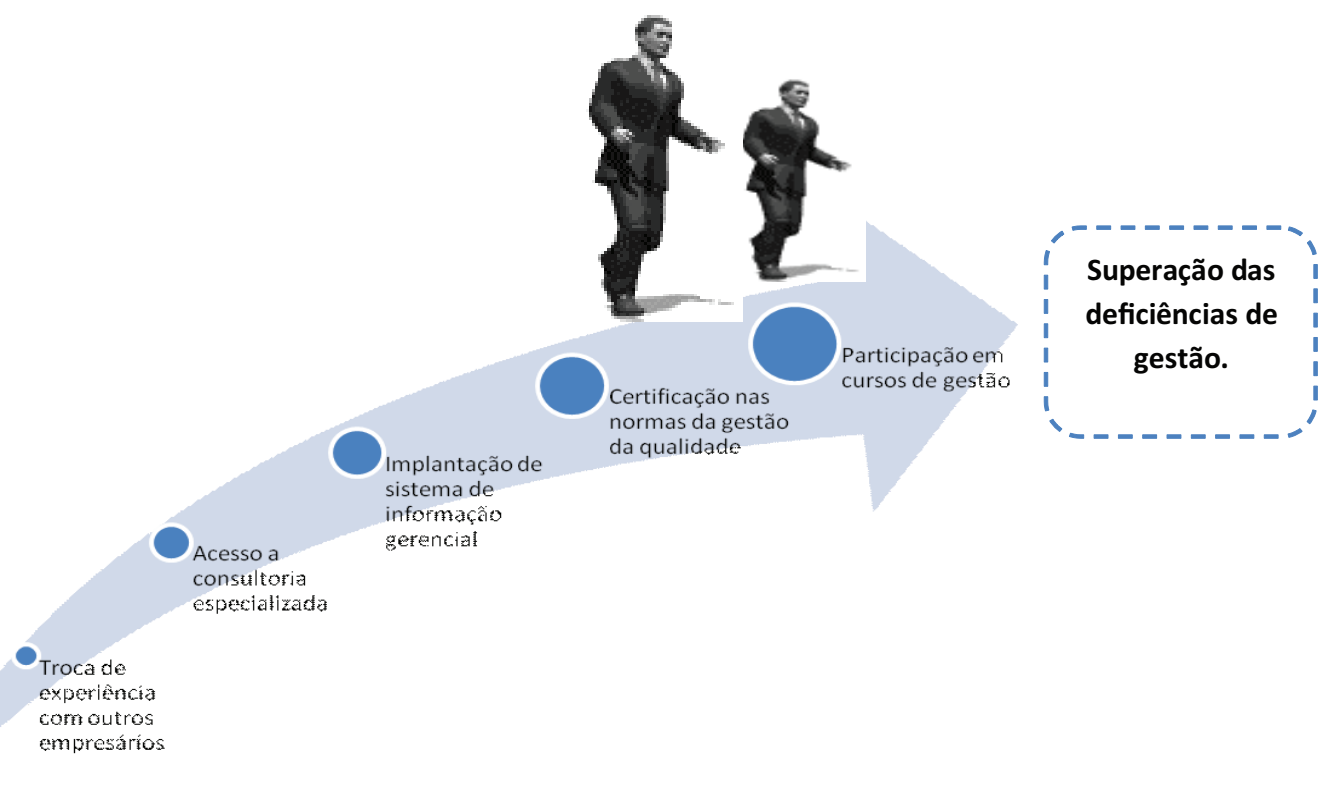

Fonte: os autores.

Figura 5 - Práticas para superar as limitações impostas pelo foco em inovação e pela competência restrita em gestão. 


\section{Conclusões}

A ênfase na complementaridade dos membros da equipe de direção e no reforço que pode ser obtido junto à rede de relação é elemento-chave para que a nova empresa tecnológica tenha não apenas competência para gerar inovações que encontram demanda no mercado, mas também para assegurar a adequada gestão dos negócios. Apesar de relativamente óbvia, esta ideia precisa ainda ser foco de atenção dos fundadores de empresas tecnológicas, de novos estudos, de programas de formação, de políticas públicas e de iniciativas dos órgãos de apoio às empresas tecnológicas para que estas tenham sua existência prolongada, possam ser mais eficientes e produzam mais benefícios para sociedade.

O surgimento de uma nova PME tecnológica está ligado a diversos fatores, dentre os quais a questão de infraestrutura, a ligação com alguma instituição de ensino e órgãos de apoio, o domínio de competências tecnológicas e o conhecimento de diferentes aspectos do funcionamento dos negócios no setor escolhido.

Os resultados apresentados permitem concluir que a busca por um sócio em empresas de base tecnológica normalmente está ligada a algum aspecto de complementaridade, seja de tempo, de gestão ou tecnológica. Ficou evidenciado também que a necessidade de complementaridade na pequena empresa de base tecnológica está relacionada às carências administrativas e à alta restrição de recursos.

Com relação aos benefícios da vocação tecnológica, ficou patente que este favorece na diminuição dos custos, a empresa obtém maior domínio do produto e uma melhor adequação ao mercado. Por outro lado, a vocação tecnológica pode levar à criação de produtos sem conexão com o mercado e a comportamentos e ações impróprias para a gestão da empresa.

As práticas utilizadas para superação da deficiência de gestão estão ligadas, principalmente, à formação do gestor, seja por meio de cursos ou pela implantação de modelos de gestão ou softwares de controle.

A ênfase na complementaridade dos membros da equipe de direção e no reforço que pode ser obtido junto à rede de relação é elemento-chave para que a nova empresa tecnológica tenha não apenas competências para gerar inovações que encontram demanda no mercado, mas também para assegurar a adequada gestão dos negócios. 


\section{Referências}

ALBERT, P. La création d'entreprises de haute technologie. In: VERSTRAETE, T. (Ed.). Histoire d'entreprendre: les réalités de l'entrepreneuriat. Paris: SEM, 2000. p. 149-160.

BORGES, C.; SIMARD, G.; FILION, L. J. Entrepreneuriat technologique - résultats de recherche sur la création d'entreprises technologique au Québec. Caderno de pesquisa. Chaire d'entrepreneuriat Rogers-J.A.-Bombardier. 2005. Disponível em: < http:// web.hec.ca/creationdentreprise/CERB_Backup12-mai-2008/pdf/2005-13CETRapport.pdf > . Acesso em: 23 jun. 2009.

CHRISTENSEN, P. V.; ULHOI, J. P.; NEERGAARD, $\mathrm{H}$. The entrepreneurial process in hightech and knowledge-based sectors in denmark. working paper. Aarhus School of Business. Aarhus University. Dinamarca. 2001. Disponível em: < http://research.asb.dk/ fbspretrieve/510/0003054.pdf > . Acesso em: 23 jun. 2009.

CLARYSSE, B.; MORAY, N. A process study of entrepreneurial team formation: the case of a research-based spin-off. Journal of Business Venturing, v. 19, n. 1, p. 55-79, 2004.

EISENHARDT, K. M. Building theories from case study research. Academy of Management Review, Briarcliff Manor, v. 14, n. 4, p. 522-550, 1989.

\section{FLICK, U. Uma introdução à pesquisa}

qualitativa. 2. ed. Porto Alegre: Bookman. 2004.

GARTNER, W.; STARR, J.; BHAT, S. Predicting new venture survival : an analysis of "anatomy of a startup" cases from Inc. Magazine. Journal of Business Venturing, n. 14, p. 215- 232, 1999.

JONES-EVANS, D. Technical entrepreneurship, experience and the management of small technology-based firms. In: JONES-EVANS, D.;KLOFSTEN, M. (Eds.). Technology, innovation and enterprise: the european experience. London: MacMillan, 1997. p. 11-60.

KAMM, J. B. et al. Entrepreneurial teams in new venture creation: a research agenda.

Entrepreneurship Theory and Practice, v. 14, n. 4, p. 7-17, 1990.

LECHLER, T. Social interaction: a determinant of entrepreneurial team venture success. Small Business Economics, v. 16, p. 263-278, 2001.

LIMA, E. Équipe de direction, vision partagée et apprentissage dans le management stratégique de PME. 2004. 381f. Tese (Doutorado em Administração), Programa conjunto de Ph.D. em Administração, HEC Montreal, Montreal, 2004. Disponível em: <www.inf.furb.br/ dalfovo/ EdmilsonLima $>$.

LIMA, E. Microdinâmicas da difusão de inovações entre micro, pequenas e médias empresas (Versão anterior disponível em http: www.inf.furb.br/ dalfovo/EdmilsonLima). In: WILHELM, P. P. H.; AMAL, M. (Orgs.). Arranjos produtivos locais: estratégias de cooperação e desenvolvimento. Blumenau: Nova Letra, 2005. p. 83-120.

LIMA, E. Relações internas e conversa estratégica nas pequenas e médias empresas. Economia e Gestão - E \& G, 2009, v. 9, p. 73-88. Disponível em: <http://periodicos.pucminas.br/index.php/ economiaegestao/article/view/725/858>. Acesso em: 20 mar. 2010.

LIMA, E. Severino, José Milton e a Benner: ícones empreendedores (caso de ensino). Belo Horizonte: Fundação Dom Cabral, 2006. Disponível em <www.inf.furb.br/ dalfovo/ EdmilsonLima $>$.

LIMA, E. Visão compartilhada, equipe de direção e gestão estratégica de pequenas empresas e médias empresas: um estudo multi-caso e internacional. Revista de Negócios, Blumenau, v. 12, n. 4, p. 86-100, outubro/dezembro, 2007a. Disponível em: <http://proxy.furb.br/ojs/ index.php/rn/article/view/668/584> . 
LIMA, E. Vision partagée, équipe de direction et conversation stratégique dans les PME. In: FILION, L. J. Management des PME : de la création à la croissance. Saint Laurent: Éditions du Renouveau Pédagogique - ERPI. 2007b. p. 367-379.

LIMA, E.; URBANAVICIUS, V. Foco na inovação e complementaridade em equipes de direção no desenvolvimento de novas empresas tecnológicas. In: SEMINÁRIO LATINO-IBEROAMERICANO DE GESTÃO TECNOLÓGICA - ALTEC, 2009, Cartagena de Índias. Anais... Cartagena de Índias, Colômbia: Asociación Latino-lberoamericana de Gestión Tecnológica, 2009.

MILES, M.B.; HUBERMAN, A.M. Qualitative data analysis: an expanded sourcebook. 2. ed. Thousand Oaks: Sage, 1994.

STOCKLEY, S.N.; BIRLEY, S. Strategic process adaptation in entrepreneurial teams: a real time micro-theoretical perspective. Proceedings of the Annual Babson Entrepreneurship Research Conference. Babson Park: Babson College. 2000. Disponível em: <http://www.babson.edu/ entrep/fer/XXVII/XXVIIB/XXVIIB.htm>. Acesso em: 20 mar. 2010.

UCBASARAN, D. et al. Entrepreneurial founder teams: factors associated with member entry and exit. Entrepreneurship Theory and Practice, v. 28, n. 2, p. 107-127, 2003.

UCBASARAN, D. et al. The dynamics of entrepreneurial teams. In: BABSON ENTREPRENEURSHIP RESEARCH CONFERENCE, Proceedings... 2001.

YIN, R.K. Estudo de caso: planejamento e métodos. 2. ed. Porto Alegre: Bookman, 2001.

ZOSCHKE, A. C. K. Marketing empreendedor e rede de relação: um estudo multi-caso de micro, pequenas e médias empresas tecnológicas de Blumenau - SC. 2006, $139 f$. Dissertação (Mestrado em Administração) Programa de Pós-Graduação em Administração, Universidade Regional de Blumenau, Blumenau. 2006. Disponível em: <http://www.inf.furb. br/ dalfovo/EdmilsonLima >. LRICH, D. Os 